\title{
The Use of a Novel Endotracheal Tube and Airway Management System to Prevent Complications in Lung Transplantation
}

\author{
Vivian Hernandez-Torres ${ }^{1}$, Robert Ratzlaff ${ }^{2}$, Mathew Thomas ${ }^{3}$, Tathagat Narula ${ }^{4}$, Archer K. Martin ${ }^{5}$ \\ 1. Department of Anesthesiology and Perioperative Medicine, Mayo Clinic, Jacksonville, USA 2. Department of Critical \\ Care, Mayo Clinic, Jacksonville, USA 3. Department of Cardiothoracic Surgery, Mayo Clinic, Jacksonville, USA 4. \\ Department of Transplantation, Mayo Clinic, Jacksonville, USA 5. Department of Cardiovascular and Thoracic \\ Anesthesiology, Mayo Clinic, Jacksonville, USA
}

Corresponding author: Archer K. Martin, martin.archer@mayo.edu

\begin{abstract}
A key component of the perioperative management of lung transplant recipients is the avoidance of airway and pulmonary complications in the immediate postoperative period. The AnapnoGuard ${ }^{\mathrm{TM}}$ AG100s (Hospitech Respiration Ltd, Kfar Saba, Israel), a novel endotracheal tube and ventilation management system, holds the potential to assist the care team in attenuating complications related to excessive cuff pressure, subglottic secretions, and endobronchial intubation. In this report, we describe the successful use of the AnapnoGuard ${ }^{\mathrm{TM}}$ AG100s system in the postoperative management of a lung transplant recipient.
\end{abstract}

Categories: Anesthesiology, Cardiac/Thoracic/Vascular Surgery, Transplantation

Keywords: lung transplantation, transplantation complications, perioperative management, mechanical ventilation

\section{Introduction}

Lung transplantation is the definitive treatment for patients with end-stage pulmonary disease [1]. However, major risks and postoperative complications can occur following transplantation, some of them being serious and resulting in a high mortality rate [2]. Pulmonary complications may occur during the immediate postoperative period and include airway complications such as anastomotic and non-anastomotic stenosis, dehiscence, torsion, and pneumothorax [3]. In addition, a postoperative course including prolonged mechanical ventilation increases the risk of bacterial colonization and infections [4].

The AnapnoGuard ${ }^{\mathrm{TM}}$ AG100s system (Hospitech Respiration Ltd, Kfar Saba, Israel) is a novel endotracheal tube (ETT) and airway management device for use in intubated patients with a promising role in the prevention of both airway and pulmonary complications after lung transplantation. The system provides continuous monitoring of leaks around the cuff based on the carbon dioxide $\left(\mathrm{CO}_{2}\right)$ level in the subglottic

Received 07/06/2019 Review began 07/09/2019 Review ended 07/10/2019 Published 07/18/2019

๑) Copyright 2019 Hernandez-Torres et al. This is an open access article distributed under the terms of the Creative Commons Attribution License CC-BY 3.0., which permits unrestricted use, distribution, and reproduction in any medium, provided the original author and source are credited. space. At the same time, the system automatically performs programmable subglottic suction of secretions via synchronized, simultaneous rinsing with saline and suction [5]. The authors present a lung transplantation case that was placed on the AnapnoGuard ${ }^{\mathrm{TM}}$ AG100s system in the postoperative period with no complications.

\section{Case Presentation}

A 53-year-old patient presented for bilateral orthotopic lung transplantation due to idiopathic pulmonary fibrosis. Initial intraoperative endotracheal intubation was achieved with the use of a left-sided doublelumen tube (DLT), and the case proceeded with central veno-arterial extracorporeal membrane oxygenation (VA ECMO) support. The patient was weaned off VA ECMO, with subsequent decannulation and chest closure. Before leaving the operating room, the DLT was exchanged to a single lumen AnapnoGuard ${ }^{\mathrm{TM}}$ ETT, and the patient was transferred to the intensive care unit on a transport ventilator. Immediately upon arrival, the patient was connected to the AnapnoGuard ${ }^{\mathrm{TM}}$ AG100s system for protective airway management. The patient was connected for four days, 15 hours, and 56 minutes without complications and the system was operated the whole period with constant regulation of ETT cuff pressures. During this time, ETT cuff pressures limits were held between 26 and $28 \mathrm{~cm} \mathrm{H}_{2} \mathrm{O}$ except during secretion removal. A total of $50 \mathrm{cc}$ of secretions were removed for the duration of intubation, and the leak test was performed 11 times, with no $\mathrm{CO}_{2}$ leaks detected. Of note, the postoperative care team was able to perform routine post-transplantation bronchoscopies via the ETT without event. On post-surgical day five, the patient failed trials with T-piece due to right diaphragmatic paralysis and underwent a tracheostomy. Eventually, diaphragmatic function recovered and the patient was successfully decannulated.

\section{Discussion}

The AnapnoGuard ${ }^{\mathrm{TM}}$ AG100s system consists of a single lumen ETT (see Figure 1), a connection kit, and a 


\section{Cureus}

control unit (see Figure 2). The ETT is a polyvinylchloride ellipsoidal tube with a thin wall polyurethane cuff, two suction lines, and an extra $\mathrm{CO}_{2}$ venting line [5]. The ETT is connected to the AG100s control unit, which provides continuous cuff pressure regulation, irrigation, and suctioning via programmable cycles [5]. The device operates automatically within these cycles, where air samples from the subglottic space are taken to measure $\mathrm{CO}_{2}$ levels and determine whether or not the cuff is sealing the trachea. The system keeps the target pressure constant, adjusting cuff pressure based on the presence or absence of $\mathrm{CO}_{2}$ levels above the cuff. If a leak is detected, the system responds by inflating the cuff to the target pressure. If a $\mathrm{CO}_{2}$ leak is not detected, the cuff pressure is reduced by $1 \mathrm{~cm} \mathrm{H}_{2} \mathrm{O}$ and is maintained using an automatic feedback loop to ensure effective sealing at minimal ETT cuff pressure [5]. Additionally, the system automatically performs programmable evacuation of airway secretions from the subglottic space via a combination of dual suction lumens and irrigation of saline to facilitate secretion removal [5]. This system has received Food and Drug Administration (FDA) and Conformité Européene (CE) approval and has been reported as a method of potentially attenuating complications related to mechanical ventilation [5-7].

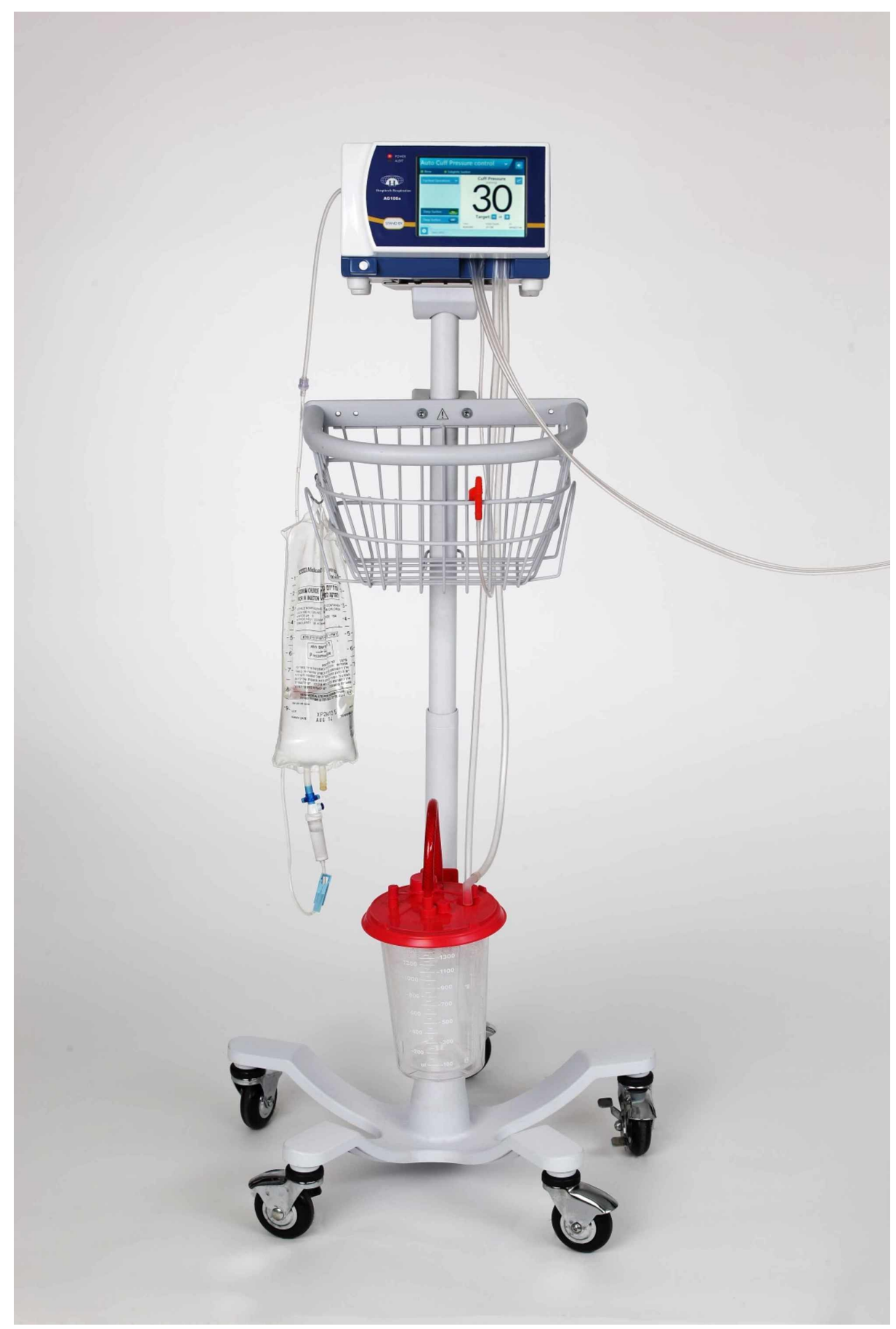

FIGURE 1: AnapnoGuard TM AG100s System. Used with permission from Hospitech Respiration Ltd. 


\section{Cureus}

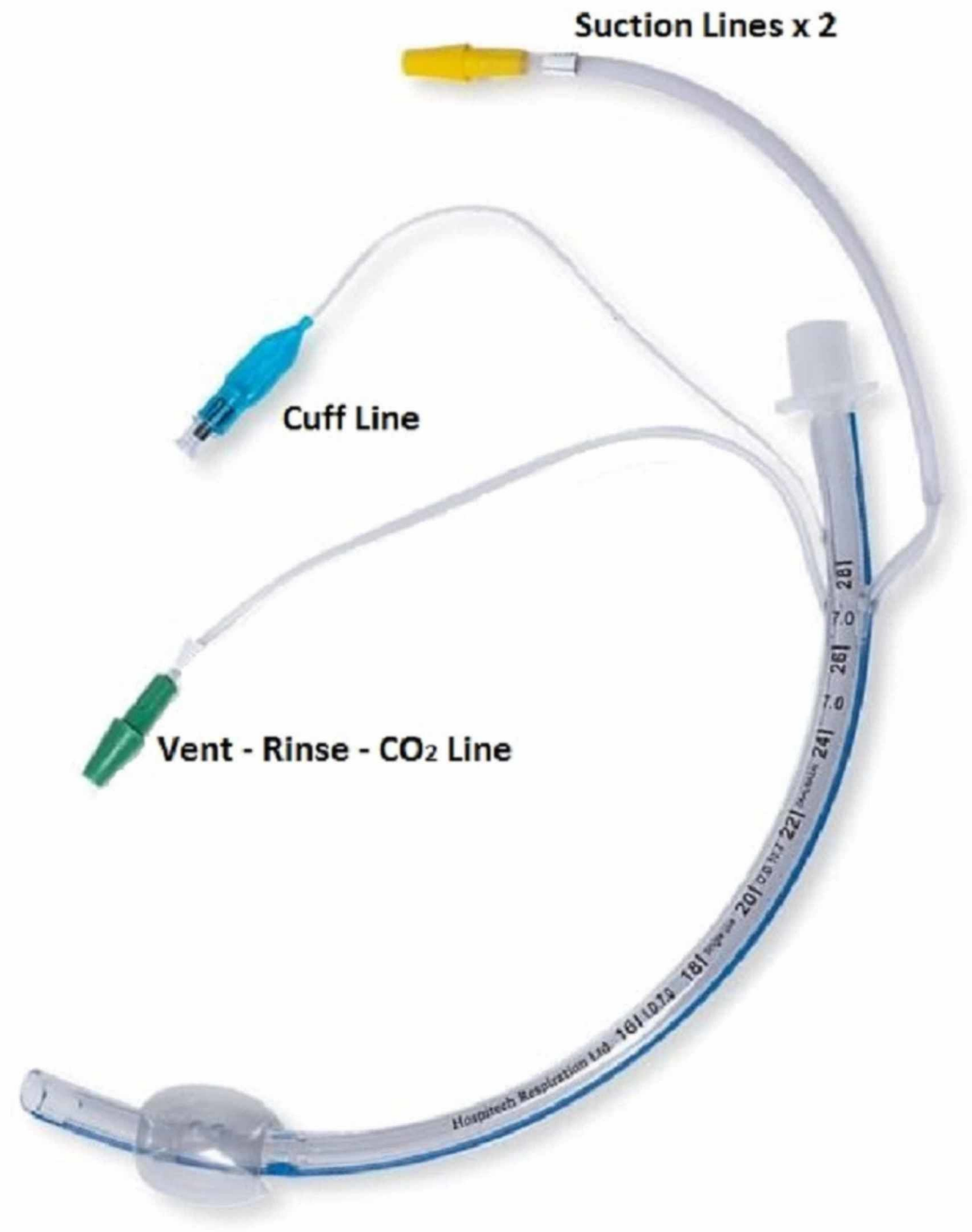

FIGURE 2: AnapnoGuard ${ }^{\mathrm{TM}}$ Endotracheal Tube. Used with permission from Hospitech Respiration Ltd.

AnapnoGuard ${ }^{\mathrm{TM}}$ (Hospitech Respiration Ltd, Kfar Saba, Israel)

The application of the AnapnoGuard ${ }^{\mathrm{TM}}$ AG100s system in the lung transplantation population has the potential to attenuate airway and pulmonary complications in the immediate postoperative period by the constant regulation of ETT cuff pressure, removal of secretions, and ability to detect endobronchial intubation. ETT cuff pressure should be regulated to provide an adequate seal while avoiding excessive pressure in order to reduce the risk of complications [8]. A minimal pressure of $20 \mathrm{~cm} \mathrm{H}_{2} \mathrm{O}$ is recommended to prevent aspiration and ventilator-associated pneumonia while a maximal of $30 \mathrm{~cm}_{2} \mathrm{O}$ has been reported to be associated with impaired tracheal wall blood supply [9]. Other complications associated with excessive pressure include postoperative hoarseness, subglottic stenosis, nerve damage, fistulas, or tracheal wall damage [9-12]. Additional safety components of the system involve suctioning airway secretions and detection of endobronchial intubation, which are key for transplanted lung graft protection by helping to prevent ETT-associated infections and diminish the risk of injury to anastomotic suture lines [13].

\section{Conclusions}

The AnapnoGuard ${ }^{\mathrm{TM}}$ AG100s system is an airway management device that provides continuous cuff pressure 
monitoring and subglottic secretion removal in mechanically ventilated patients. When using this device in our patient, we observed quantitative removal of secretions, lack of cuff leak, and successful use of postoperative surveillance bronchoscopies via the AnapnoGuard ${ }^{\mathrm{TM}}$ ETT. Future clinical studies are needed to determine the impact of this system on airway and pulmonary complications after lung transplantation.

\section{Additional Information \\ Disclosures}

Human subjects: Consent was obtained by all participants in this study. Conflicts of interest: In compliance with the ICMJE uniform disclosure form, all authors declare the following: Payment/services info: All authors have declared that no financial support was received from any organization for the submitted work. Financial relationships: All authors have declared that they have no financial relationships at present or within the previous three years with any organizations that might have an interest in the submitted work. Other relationships: All authors have declared that there are no other relationships or activities that could appear to have influenced the submitted work.

\section{References}

1. Martin AK, Renew JR, Jayaraman AL, Murray AW, Fritz AV, Ramakrishna H: Analysis of outcomes in lung transplantation. J Cardiothorac Vasc Anesth. 2019, 33:1455-1466. 10.1053/j.jvca.2018.06.014

2. de la Torre M, Fernandez R, Fieira E, Gonzalez M, Delgado M, Mendez L, Borro JM: Postoperative surgical complications after lung transplantation. Rev Port Pneumol. 2006, 21:36-40. 10.1016/j.rppnen.2014.09.007

3. Tejwani V, Panchabhai TS, Kotloff RM, Mehta AC: Complications of lung transplantation: a roentgenographic perspective. Chest. 2016, 149:1535-1545. 10.1016/j.chest.2015.12.019

4. Hunter JD: Ventilator associated pneumonia. BMJ. 2012, 344:3325. 10.1136/bmj.e3325

5. De Pascale G, Pennisi MA, Vallecoccia MS, et al.: CO2 driven endotracheal tube cuff control in critically ill patients: a randomized controlled study. PLoS One. 12:0175476. 10.1371/journal.pone.0175476

6. Efrati S, Deutsch I, Weksler N, Gurman GM: Detection of endobronchial intubation by monitoring the CO2 level above the endotracheal cuff. J Clin Monit Comput. 29:19-23. 10.1007/s10877-014-9583-5

7. Efrati S, Leonov Y, Oron A, Siman-Tov Y, Averbukh M, Lavrushevich A, Golik A: Optimization of endotracheal tube cuff filling by continuous upper airway carbon dioxide monitoring. Anesth Analg. 2005, 101:1081-1088. 10.1213/01.ane.0000167641.64815.1a

8. Stauffer JL, Olson DE, Petty TL: Complications and consequences of endotracheal intubation and tracheotomy. A prospective study of 150 critically ill adult patients. Am J Med. 70:65-76. 10.1016/00029343(81)90413-7

9. Hameed AA, Mohamed H, Al-Mansoori M: Acquired tracheoesophageal fistula due to high intracuff pressure. Ann Thorac Med. 3:23-25. 10.4103/1817-1737.37950

10. Otani S, Fujii H, Kurasak N, et al.: Recurrent nerve palsy after endotracheal intubation [Article in Japanese] . Masui. 1986, 47:350-355.

11. Spittle N, McCluskey A: Lesson of the week: tracheal stenosis after intubation . BMJ. 2000, 321:1000-1002. 10.1136/bmj.321.7267.1000

12. Rouze A, Nseir S: Continuous control of tracheal cuff pressure for the prevention of ventilator-associated pneumonia in critically ill patients: where is the evidence?. Curr Opin Crit Care. 2013, 19:440-447. 10.1097/MCC.0b013e3283636b71

13. Combes P, Fauvage B, Oleyer C: Nosocomial pneumonia in mechanically ventilated patients, a prospective randomised evaluation of the Stericath closed suctioning system. Intensive Care Med. 2000, 26:878-882. 